\title{
Metodologia de Ensino em Psicologia Médica e Atenção Integral ao Paciente
}

\author{
Teaching Methods on Medical Psychology \\ and Integrated Care for Patients
}

Cristiane Curi Abud Vera Blondina Zimmermann ${ }^{I}$ Ana Cecilia Lucchese ${ }^{I}$ Mario Alfredo De Marco ${ }^{I}$

\section{PALAVRAS-CHAVE}

- Psicologia Médica.

- Metodologia.

- Entrevista Psicológica.

- Educação Médica.

\section{KEYWORDS}

- Medical Psychology.

- Methodology.

- Psychological Interview.

- Medical Education.
Recebido em: 15/02/2012

Aprovado em: 05/08/2012

REVISTA BRASILEIRA DE EDUCAÇÃO MÉDICA

\section{ABSTRACT}

We report on this article our teaching experience in Medical Psychology Course for second-year graduation students of Medical School of UNIFESP-EPM, which has shown efficient for sensitizing and for training students to observe, to perceive and to evaluate patients' mental and emotional state. From discussion of theoretical fields of knowledge like History of Medicine, Communication Theories, Psychiatry, Psychoanalysis and Developmental Psychology, we prepare students for their clinical practice through patients' interviewing. We created a guideline which offers a reference of basic issues that must be addressed and that must be noted at patients' interviews, which guide on how to interview and also on how to do a written report. In a dialectical relation they study theories and they try theories' application, they interview patients and they write reports on practical experience combined with theories. 
Como entrevistar um paciente? O que devemos perguntar? Devemos ter um questionário fechado de temas a serem investigados ou devemos deixar o paciente falar livremente? Em que momento interromper a fala do paciente? Como interromper? Como observar, durante uma entrevista clínica, o estado psíquico e emocional do paciente? E se o paciente chorar, o que eu faço com isso?

Essas e tantas outras são perguntas muito frequentes dos alunos do curso de graduação de Medicina. Perguntas que surgem na graduação, mas que acompanham o profissional de saúde ao longo de sua experiência profissional. Na tentativa de orientar o processo de aprendizagem dos alunos com relação aos aspectos humanos de uma entrevista clínica, desenvolvemos, ao longo de anos de experiência ministrando o curso de Psicologia Médica para alunos do segundo ano da graduação de Medicina, uma metodologia que vem se mostrando bastante profícua.

Em princípio, destacamos de alguns campos de conhecimento científico temas, conceitos e ilustrações que possam ajudar o aluno a organizar sua experiência de campo junto aos pacientes.

Ao longo do curso, abordamos os temas que relacionamos à entrevista clínica, provenientes da História da Medicina, da Comunicação, da Psiquiatria, da Psicanálise, da Psicologia do Desenvolvimento e da Psicologia Médica. Um caminho teórico e prático planejado e replanejado, muitas vezes, levando em conta acertos e erros, bem como modificações em função das diferenças, limites e resistências com os quais nos deparamos durante o processo de ensino-aprendizagem. Oferecemos ao leitor o que fomos selecionando enquanto questões básicas sobre o processo de subjetivação humana, abordando alguns fenômenos que podem se apresentar no dia a dia do trabalho do médico sem exigir dele aprofundamentos teóricos em assuntos que não lhe cabe diagnosticar e intervir diretamente. Optamos por fornecer-lhe informações norteadoras que o ajudem a transitar pelos fenômenos psíquicos e, desta forma, habilitá-lo melhor para sua tarefa.

A partir dos recortes desses campos de conhecimento e de nossa experiência, criamos um roteiro de entrevista, que visa não engessar o aluno/entrevistador, mas oferecer um norte, uma referência geral dos temas básicos que devem ser abordados e observados na entrevista com os pacientes. Os roteiros orientam não apenas o momento da realização das entrevistas, como também sua organização posterior sob a forma de um relatório escrito. Numa relação dialética, os alunos estudam e ensaiam aplicações da teoria, realizam as entrevistas e escrevem relatórios sobre a experiência prática articulada com a teoria.
Essa metodologia escapa e se diferencia da metodologia predominante nas escolas médicas brasileiras, qual seja, segundo Krasilchik ${ }^{1}$, a racionalista-acadêmica, que entende ser função da escola transmitir aos alunos o acervo cultural acumulado por meio de aulas expositivas, nas quais o professor expõe o saber e o aluno "basicamente recebe informações já organizadas e categorizadas" (p. 6). Nota-se que a escolha do método de ensino não é neutra ${ }^{2}$, mas reflete intencionalidade de ação, que comporta uma visão sobre o mundo, sobre a educação, sobre a missão da escola médica, sobre a saúde, sobre a doença. Assim, uma metodologia centrada predominantemente na transmissão por meio da comunicação oral, em aulas expositivas dadas pelos professores, e da avaliação mediante provas tradicionais ${ }^{3}$ reflete uma visão que restringe o indivíduo à sua dimensão biológica, relevando, ou até mesmo recusando, seus aspectos humanos. Por meio do ensino da semiologia, devidamente memorizada pelos alunos, realiza-se a "clínica da decifração", expressão criada por Foucault $^{4}$. Na clínica, o estudante fará uma entrevista e um levantamento dos sintomas para enquadrar a doença num quadro nosológico preestabelecido e dar um nome diagnóstico a ela. Trata-se de uma decifração mais do que de um exame. A clínica não é em si mesma uma experiência, mas uma reconfirmação do que já se sabe, uma demonstração mais do que uma descoberta. Impede a descoberta e o pensamento criativo.

Nesse modelo, tudo aquilo que é humano incomoda e atrapalha o processo de decifração. A situação pedagógica, na sala de aula, repete esse modelo de relação médico-paciente. $\mathrm{O}$ professor, assim como o médico, é aquele que sabe, que conhece a chave da decifração e que irá ensinar-educar o aluno, assim como o médico ensina seu paciente. E o aluno deve seguir suas instruções, assim como o paciente segue suas prescrições. Tal modelo transcende a simples assimetria reguladora presente na relação médico-paciente ou professor-aluno, transmutando-se em uma rígida hierarquia, através da qual o saber se transforma em poder.

No que se refere ao conteúdo ensinado no curso, optamos por começar a apresentação das áreas de conhecimento pela História da Medicina, por considerarmos que, numa entrevista clínica, além da história dos sintomas e da doença apresentada pelos pacientes, é fundamental conhecer a história da vida do paciente. Qual é o seu nome e seu sobrenome, sua idade, onde nasceu, quem são seus pais, sua escolaridade, sua cultura, profissão, religião, grupo social e sua forma de se relacionar com as pessoas à sua volta, com a vida e com a doença. Todo sintoma, toda doença e toda dor têm uma história. A doença aparece em determinado contexto histórico, psíquico e 
social. É certo que existem predisposições genéticas e biológicas, que fariam do aparecimento da doença algo simplesmente "natural". Entretanto, observamos que raramente o aparecimento dos sintomas referidos pelos pacientes é alheio à sua contingência histórica, psíquica e social. E mesmo que o aparecimento seja ou pareça alheio, uma vez instalada, a doença deve ser integrada — tanto pelo paciente quanto pelo médico - a esse contexto de vida mais amplo. Por exemplo, como a mãe de duas crianças, de quatro e três anos, administra o câncer de mama que surgiu e a obriga a se ausentar de casa para tratá-lo quase diariamente? Ela é casada? Conta com o apoio de familiares? Conta com o apoio da mãe ou esta já faleceu de câncer de mama, que, como se sabe, é altamente hereditário? Ela tem medo de falecer como a mãe? Tem medo de que seus filhos padeçam do mesmo mal? Ela deve conversar com as crianças sobre sua doença? Como explicar a elas sua ausência? Em suma, qual é a história dessa família e como seus integrantes lidam com a vida e com a doença?

A história da medicina tampouco é uma história "natural", na qual o saber e as práticas médicas sempre existiram independentemente de seu contexto social, histórico e cultural. E para que o aluno possa contextualizar o conhecimento atual do campo e criar uma distância crítica e reflexiva em relação à sua formação e atuação profissional, consideramos necessário conhecer a história da medicina. Conhecer, por exemplo, o fato de que Hipócrates ${ }^{5}$ perguntava a seus pacientes com que eles sonhavam, quais eram seus receios e suas esperanças - perguntas que foram abolidas da anamnese médica por questões históricas, cultural e socialmente determinadas, e não necessariamente por motivos científicos.

Ora, perguntaria o aluno, mas por que um médico precisa saber se o paciente tem receios, o que isso tem a ver com medicina? Como isso poderia interferir no tratamento de uma doença?

Em entrevista realizada pelos alunos do segundo ano do curso de graduação de Medicina da Unifesp, Joãozinho, um paciente de cinco anos de idade, revelou um sonho aos entrevistadores: ele passeava na rua quando um urubu enorme voou em sua direção, atingindo-o e derrubando-o no chão. $\mathrm{O}$ garoto revelou ainda que durante o sonho sentiu muito medo do urubu. Ora, esse rapazinho estava internado para realizar a terceira cirurgia no pé esquerdo, que corrigiria uma lesão causada por um atropelamento. Passeando com a mãe na rua, Joãozinho foi atingido por um carro e seu pé foi gravemente ferido. Outra informação importante observada pelos alunos consistia no fato de que cada enfermeira ou profissional que se aproximava do leito do paciente para realizar algum procedimento gerava nele um estado de pânico, dificultando enorme- mente o trabalho da equipe, além de aumentar as dores dele - segundo a equipe médica, a intensidade das queixas de dor do menino não se justificavam pelas lesões do pé.

Voltando à importância da história enquanto campo de saber que organiza a prática da entrevista, a mãe de Joãozinho forneceu um dado importante para compreendermos os receios revelados pelo sonho e o comportamento do menino diante da equipe de profissionais: seu pai saíra de casa havia um ano, tendo sido expulso pela mãe, uma vez que bebia muito e se tornava agressivo com a família. Inconformado, o pai fazia ameaças á esposa e aos filhos, e uma dessas ameaças foi feita no dia em que Joãozinho foi atropelado.

Vejamos que outras teorias podem ser úteis para a compreensão e a condução desse fragmento clínico. A começar pela Comunicação, outro campo do saber selecionado no curso para orientar a prática da entrevista: se os alunos não tivessem utilizado a entrevista semiestruturada, que apresenta perguntas fechadas, mas abre um espaço de conversa às demandas do paciente, provavelmente Joãozinho não nos teria contado seu sonho. Tampouco os alunos teriam notado a comunicação não verbal de Joãozinho, que desde sua expressão corporal e facial - tensa e retraída - até seu tom de voz — baixo, trêmulo e voltado para dentro - revelava um fundo emocional de medo e de receio.

Assim, o uso de técnicas de entrevista apropriadas, como, por exemplo, o silêncio funcional, permite estabelecer uma relação de confiança com o paciente - mesmo um paciente receoso como Joãozinho -, que se sente à vontade para revelar sua história, seus receios e suas esperanças. Isto possibilita ao profissional colher informações importantes para a formulação de um diagnóstico correto e para uma condução e manejo clínicos menos ameaçadores ao paciente. Os alunos puderam, inclusive, avaliar que, do ponto de vista do exame psíquico, Joãozinho não apresentava nenhuma alteração de pensamento, sendo sua forma agregada, seu curso normal. Destacamos esse dado observado pelos alunos, uma vez que os receios de Joãozinho poderiam, além de não encontrar fundamentos em sua história de vida e na história de sua doença, hipótese não confirmada pelos dados até então revelados, habitar um psiquismo comprometido, paranoico, hipótese também não confirmada pelo exame psíquico.

Do ponto de vista do funcionamento psíquico e da experiência subjetiva da doença, e aqui nos apoiamos na teoria psicanalítica, Joãozinho apresentava uma realidade psíquica bastante compatível com a situação de vida em que estava inserido. Tinha um pai agressivo que o perseguia e ameaçava, o que naturalmente gera medo e receio em qualquer pessoa, e foi atropelado por um carro no dia em que a família recebeu uma 
dessas ameaças, o que confirma seus medos e receios, conferindo-lhes uma concretude ainda maior. Seu sonho revela o receio de ser atacado por esse pai-carro-urubu, assim como na relação com os profissionais de saúde ele se sente ameaçado, sendo que a cadeia pai-carro-urubu ganha mais um componente: pai-carro-urubu-profissional de saúde. Ou seja, na relação transferencial, o paciente coloca a equipe médica no lugar do pai que ameaça sua integridade física. A experiência subjetiva da dor ganha, neste contexto psíquico e emocional, uma amplificação afetiva: o medo. Para organizar essas ideias, nos valemos de conceitos psicanalíticos, como subjetividade, realidade psíquica, mecanismos de defesa, transferência e contratransferência.

Destacamos ainda noções oriundas da Psicologia do Desenvolvimento, que oferecem uma referência do que é esperado nas várias fases do desenvolvimento durante o ciclo de vida e morte. Por exemplo, aos cinco anos de idade, as crianças costumam ser egocêntricas, ou seja, estabelecem relações causais que envolvem a sua pessoa, tendendo a se sentir culpadas ou responsáveis por tudo o que acontece à sua volta. Não seria, portanto, estranho se Joãozinho se sentisse responsável pela braveza do pai e pela decorrente separação dos pais, e esperasse, receosamente, o tempo todo ser castigado por isso. Neste sentido, o atropelamento pode adquirir um significado de punição, assim como todos os procedimentos médicos realizados.

Finalmente, do campo da Psicologia Médica, recortamos teorias e noções que, no âmbito emocional e psíquico, indicam que reações o paciente pode apresentar como parte do processo de adoecer e como a equipe de saúde pode manejar essas situações clínicas, conjugando às intervenções técnicas a observância dos aspectos emocionais e éticos implicados na tarefa. No caso de Joãozinho, como a equipe de saúde poderia manejar a situação de forma a tornar o tratamento menos dolorido para o paciente? O simples fato de discriminar que a dor física era amplificada pela dor psíquica originada pelos conflitos familiares já seria de grande valia para os profissionais. Poder conversar com Joãozinho, dizer que seu medo é natural, que os adultos são complicados e que as crianças não têm que se responsabilizar por isso poderia aliviá-lo. A cada procedimento, explicar o que será feito, como e quais as consequências dos procedimentos; pedir permissão para realizá-los; pedir permissão para tocar o corpo de Joãozinho; mostrar que percebemos que ele já se sente muito machucado e que serão tomados todos os cuidados necessários para não machucá-lo ainda mais, etc. Enfim, básica e resumidamente, mostrar ao paciente que não iremos tratá-lo como seu pai, que o ameaça, ou o carro e o urubu, que o atropelaram sem pedir licença.
Pelo contrário, a equipe demonstrará que percebe e respeita sua dor e seus medos, e que, além dos procedimentos técnicos, irá lhe emprestar coragem para enfrentá-los.

Conforme mencionado, o estudo da teoria e as ilustrações e vivências que vão sendo trabalhadas ao longo do curso organizam a prática da entrevista, mas essa experiência deve ainda passar por mais um processo de elaboração: a confecção de relatórios escritos que integrem e articulem a teoria e a prática.

Os relatórios escritos pelos alunos são instrumentos dinâmicos, nos quais o estudante registra e organiza suas entrevistas de forma sistematizada por meio do discurso narrativo, contínuo e reflexivo. A reflexão - acerca dos fatos e de si - é um processo em que o sujeito atribui sentido a uma situação e por isso deve ser crítica e autocrítica.

A narração é uma história, um discurso com significação. Assim, solicitamos que escrevam narrativamente, em primeiro lugar, os fatos narrados pelo paciente. Dados de história de vida passada e atual devem ser registrados o mais proximamente possível do discurso do paciente. A realidade psíquica do paciente é diferente de sua realidade histórica, e devemos investigar os fatos para, com base neles, encontrar o sentido psíquico que o paciente atribui aos mesmos.

Após transcrever os dados fornecidos pelo paciente identificação, história de vida, história da doença, dados sobre a família, o trabalho, o grupo social, a relação com o hospital (ambiente e profissional) -, o aluno deve relacionar esses fatos com aspectos teóricos apreendidos e vivenciados no curso preparatório. Descrever o paciente, sua comunicação não verbal, sua maneira de se comunicar, seu exame psíquico, seus mecanismos de defesa, aspectos transferenciais e contratransferenciais; enfim, conceitos que possam servir à melhor compreensão do paciente quanto a seu funcionamento psíquico, sua personalidade, sua forma de se relacionar com os outros e com a própria saúde. Ao refletir sobre conceitos como comunicação não verbal do paciente, o aluno pode, inclusive, comparar os dados obtidos por meio do discurso do paciente com os dados observados diretamente no paciente. Por exemplo, um aluno entrevistou, na pediatria, o pai de uma criança que cheirava a álcool no período da manhã. Trata-se de um dado da comunicação não verbal que pode comprometer a veracidade dos fatos relatados pelo pai.

Finalmente, o aluno deve realizar uma autorreflexão, levantando aspectos da entrevista que despertaram sua atenção, que trouxeram dificuldades ou indagações, temores, gratificação e alegrias.

Os relatórios, que um dia se tornarão anamneses escritas e registradas nos prontuários dos pacientes, serão os instrumentos de comunicação de que os profissionais de saúde dis- 
põem para sua comunicação com colegas e, portanto, devem ser assimilados e bem redigidos.

A entrevista realizada com Joãozinho foi narrada pelos alunos, que só então se deram conta das diversas teorias que usaram na prática e, principalmente, do quanto se sentiram ameaçadores para Joãozinho, tendo por vezes dificuldade em fazer perguntas por medo de gerar uma reação adversa no paciente. Percebendo que estavam incluídos na série pai-carro-urubu-profissionais de saúde-entrevistadores, os alunos puderam dar um significado ao seu receio de fazer perguntas e machucar o paciente, receios que, de outra forma, talvez fossem interpretados pelos alunos como insegurança pessoal do tipo "eu não sirvo para isso", "sou muito tímido para entrevistar" ou "não levo jeito com pacientes". Noções equivocadas sobre a experiência com o paciente, noções que permaneceriam como inibidores nas próximas entrevistas.

Assim, além da articulação entre teoria e prática, é necessária uma reflexão, para que o profissional possa conferir algum significado a situações de vida tão dolorosas quanto a de Joãozinho. O processo de significação afetiva da experiência ajuda a aliviar a dor psíquica do paciente e do profissional que o assiste.

Finalmente, pensamos e elaboramos a avaliação do curso de forma coerente com a filosofia, a visão de saúde-doença até aqui exposta. Cada relatório escrito pelos alunos é lido e avaliado pelo professor a fim de ampliar a capacidade de observação e articulação com a teoria. Seguindo o modelo de uma supervisão clínica, o professor deve apontar os conteúdos que foram bem coletados da história de vida e do processo saúde-doença do paciente, assim como os conteúdos que faltaram e que amplificariam a compreensão do caso. O professor deve ainda orientar sobre as dúvidas, que devem fazer parte dos relatórios, com relação à técnica de entrevista, com relação a sensações contratransferenciais, etc. Outra função da avaliação é promover maior articulação com a teoria, salientando aspectos, por exemplo, sobre o desenvolvimento. Enfim, a avaliação serve para auxiliar o aluno a realizar o difícil percurso entre teoria e prática, sendo importante verificar, mais do que o desempenho num relatório isoladamente, a evolução do aluno ao longo do semestre, a capacitação que adquire entre um relatório e outro. Desta forma, passamos de uma avaliação puramente somativa/punitiva no final das unidades para uma avaliação formativa, com constantes feedbacks ${ }^{6}$.

Após cinco anos de experiência com o método descrito, concluímos que sensibilizamos os alunos da graduação de Medicina a escutar os pacientes e a avaliar seu estado psíquico e emocional, o que deverá ser aprofundado e aprimorado ao longo do curso de graduação.

\section{ROTEIRO PARA CONFECÇÃO DO RELATÓRIO?}

\section{Criança de 3 a 6 Anos}

1. Identificação: nome, sexo, idade, procedência, estado civil, grau de instrução, profissão, naturalidade, nacionalidade.

2. História de vida e desenvolvimento atual: vida dos pais, de seus familiares, da gestação, foi planejada? Foi desejada? Como foi o recebimento da notícia? Quais eram as expectativas em relação ao bebê (sexo, personalidade, saúde)? Como o marido reagiu à gravidez de forma geral? Como foi o parto? E o puerpério, como está sendo ou foi? O bebê teve alta hospitalar? Como a mãe se sentia emocionalmente? Como foi voltar para casa e retomar os cuidados da casa, marido, filhos? Como foi voltar ao trabalho, separar-se do bebê? Como era o bebê se comparado ao que ela imaginou durante a gravidez? O bebê chorava? Dormia? O que a mãe fazia quando ele chorava? O bebê se acalmava? O bebê buscava se comunicar com a mãe e reagia de alguma forma, chamando a atenção do adulto quando este não prestava atenção nele? A mãe amamentou? Como se sentia? Amamentava sempre que o bebê chorava? Sabia distinguir o choro de "manha'? Desmamou? Como foi o desmame para o bebê? E para a mãe? A criança anda? Com que idade começou a andar? Como isso modificou o contexto da casa? A criança tem ou tinha vontades (escolher a própria roupa)? A criança usa fraldas? Se não, como foi ou está sendo o processo de tirá-las? A criança fala? Diz muito "não"? Como os pais reagem às iniciativas da criança? Tendem a incentivar ou a brecar suas iniciativas motoras e linguísticas? A criança se aborrece com a bronca dos pais? Obedece aos pais? Sempre? A criança tem algum objeto ao qual se agarra na ausência dos pais? Chegou algum irmãozinho novo? Como foi a reação diante dele? Como é o sono da criança? Como é sua alimentação? A criança se machuca muito? Tem doenças respiratórias?

3. História da doença: no dia em que apareceram os primeiros sintomas, descreva detalhadamente o que o paciente e a família estavam fazendo e se havia alguma situação extraordinária acontecendo (separação, divórcio, perda de emprego, falecimento na família, estresses ou traumas de forma geral).

4. A família: constituição, relacionamento familiar e impacto da doença na família.

5. A escola: relacionamento com a escola, professores e amigos, e impacto da doença na escola. 
6. O grupo social: características da inserção social e cultural e impacto da doença no contexto social.

7. O ambiente hospitalar e profissionais da saúde: impressão geral sobre o hospital e relacionamento com a equipe de saúde.

8. Observação da criança: consegue abotoar uma camisa? Desenha figuras? Figuras humanas? Com que formas e tamanhos? Pergunta muito os "porquês"? Se vir uma bola vindo de trás da parede, tenta ver quem a chutou? Consegue organizar categorias de objetos? Consegue lidar com quantidades, por exemplo, dividir balas? Percebe se alguém está chateado? Consegue distinguir pensamentos de sonhos? Distingue o real do imaginário? Papai Noel existe? A criança se "despede do balanço"? Como é sua linguagem? Como a criança se autodescreve? Consegue conciliar o desejo de fazer alguma coisa com o desejo de aprovação dos pais (conciliar atitude e culpa)? É menino ou menina? Como é sua identidade de gênero, compatível com sua cultura? Brinca? Brinca de faz de conta? Descreva detalhadamente uma brincadeira que a criança tenha proposto? Como é seu julgamento moral?

9. Articulação da observação com os aspectos teóricos e práticos já discutidos (psicologia do desenvolvimento, técnicas de comunicação e entrevista, transferência e contratransferência)

10. Aspectos, vivências, indagações e dificuldades da entrevista que despertaram a atenção.

\section{REFERENCIAS}

1. Krasilchik M. Planejamento educacional: estruturando o currículo. In: Marcondes E, Gonçalves EL. Educação Médica. São Paulo: Sarvier; 1998.
2. Ribeiro ECO. Ensino/aprendizagem na escola médica. In: Marcondes E, Gonçalves EL. Educação Médica. São Paulo: Sarvier; 1998.

3. Masetto MT. Discutindo o processo ensino/aprendizagem no ensino superior. In: Marcondes E, Gonçalves EL. Educação Médica. São Paulo: Sarvier; 1998.

4. Foucault M. O nascimento da clínica. Rio de Janeiro: Forense Universitária; 2006.

5. Volich RM. Psicossomática: de Hipócrates à psicanálise. São Paulo: Casa do Psicólogo; 2000.

6. Zanolli MB. Metodologias ativas de ensino aprendizagem na área clínica. In: Marins JJN, Rego S, Lampert JB, Araujo JGC. Educação Médica em transformação: instrumentos para a construção de novas realidades. São Paulo: Hucitec; 2004.

7. Abud CC. Sobre os relatórios de entrevista. In: De Marco et al. Psicologia Médica: abordagem integral do processo saúde-doença. Porto Alegre: Artmed Editora; 2012.

\section{CONTRIBUIÇÃO DOS AUTORES}

Mario Alfredo De Marco colaborou para a implantação do método e escrita do artigo. Ana Cecilia Lucchese e Vera Blondina Zimmermann colaboraram para a escrita do artigo.

\section{CONFLITO DE INTERESSES}

Declarou não haver.

\section{ENDEREÇO PARA CORRESPONDÊNCIA}

Cristiane Curi Abud

Al. Joaquim Eugenio de Lima, 881 — cj. 1105

Jardim Paulista — São Paulo

CEP 01403-001 — SP

E-mail: criscabud@uol.com.br 